\title{
Genetic Diversity and Lineage Based on SSR Markers of Two Genomic Resources among Trifolium Collections Held within the Australian Pastures Genebank
}

\author{
Devendra R. Malaviya1 ${ }^{*}$, Harsh Raman², Brian S. Dear², Rosy Raman', \\ Ajoy K. Roy ${ }^{3}$, Pankaj Kaushal ${ }^{4}$, Amaresh Chandra1, Steve J. Hughes ${ }^{5}$ \\ ${ }^{1}$ ICAR - Indian Institute of Sugarcane Research, Lucknow, India \\ ${ }^{2}$ Graham Centre for Agricultural Innovation, Wagga Wagga, Australia \\ ${ }^{3}$ ICAR - Indian Grassland and Fodder Research Institute, Jhansi, India \\ ${ }^{4}$ ICAR - National Institute of Biotic Stress Management, Raipur, India \\ ${ }^{5}$ South Australian Research \& Development Institute, Urrbrae,, Australia \\ Email: *malaviya2007@yahoo.co.in
}

How to cite this paper: Malaviya, D.R., Raman, H., Dear, B.S., Raman, R., Roy, A.K., Kaushal, P., Chandra, A. and Hughes, S.J. (2019) Genetic Diversity and Lineage Based on SSR Markers of Two Genomic Resources among Trifolium Collections Held within the Australian Pastures Geneban. Open Journal of Genetics, 9, 1-14. https://doi.org/10.4236/ojgen.2019.91001

Received: January 3, 2019

Accepted: February 22, 2019

Published: February 25, 2019

Copyright $\odot 2019$ by author(s) and Scientific Research Publishing Inc. This work is licensed under the Creative Commons Attribution International License (CC BY 4.0).

http://creativecommons.org/licenses/by/4.0/

c) (†) Open Access

\begin{abstract}
Trifolium alexandrinum, an important forage legume, suffers from narrow genetic base. The present investigation was envisaged to reveal the inter- and intra-species genetic diversity and lineage among 64 accessions, representing a global collection, of $T$. alexandrinum; it's two probable progenitor species (T. salmoneum and T. subterraneum) and the three genetically distant species (T. repens, T. vesiculosum, T. michelianum). A set of Simple Sequence Repeats (SSR) primer-pairs developed from $T$. alexandrinum have shown to amplify alleles across the species under study, suggesting utility of the newly developed resource for assessing molecular diversity among Trifolium species. These SSRs markers together with previously reported SSRs, derived from $T$. repens, enabled to reveal high intra-species polymorphism in $T$. alexandrinum and successfully discriminate different species investigated in this study. The diverse accessions determined herein provide a superior resource for further breeding of $T$. alexandrinum. High allelic similarity of $T$. alexandrinum with T. subterraneum and T. salmoneum indicated close relatedness among the species, suggesting polyphyletic evolution of $T$. alexandrinum.
\end{abstract}

\section{Keywords}

Egyptian Clover, Evolution, Genetic Resource, Molecular Diversity 


\section{Introduction}

Genus Trifolium, of the family Leguminosae (Fabaceae), comprises more than 237 annual and perennial species [1]; of which 20 are recognized for forage value. T. alexandrinum (Egyptian clover or Berseem), one of the most important forage crops, is cultivated across the globe. It is grown in a wide range of environments across Egypt, India, Australia, Pakistan and Middle East countries [2]. It is a popular fodder crop among growers because of its several desirable attributes: high biomass yield (120 t/ha green), protein content (23\%), dry matter digestibility (65\%) and multi-cut nature (4 to 8 cuts). Besides, it improves soil fertility through symbiotic nitrogen fixation and thus reduces carbon footprint in production and application of nitrogen fertilizers in agricultural landscape. During last 30 years, significant genetic progress has been made in this crop that enabled to the development of improved cultivars. However, in addition to genetic bottleneck during domestication, selective breeding has further narrowed down the genetic base of $T$. alexandrinum, especially in breeding germplasm.

Various methods such as morphological, biochemical and molecular markers have been deployed to assess the extent of genetic diversity in crop plants including Indian collection of the Trifolium [3] [4] [5] [6]. These studies have shown a limited genetic and molecular diversity among $T$. alexandrinum accessions, suggesting that novel alleles for useful traits such as resistance to biotic and abiotic stresses are required to make rapid genetic gain in this species.

Germplasm collections held at various genebanks provide diverse source of naturally occurring genetic variation which can be exploited for trait improvement. Australian Pastures and West Australian Gene Banks have a collection of diverse accessions of T. alexandrinum, T. repens (white clover), T. subterraneum (subterranean clover), T. salmoneum, T. vesiculosum (arrow clover), and $T$. michelianum (balansa clover). So far, these accessions have not been characterized. Therefore, it is important to characterize this set of germplasm so that forage breeders can target accessions of interest and utilize them effectively in their national breeding programs. SSR markers have been extensively used in the genome and genetic analysis of various crops due to their high repeatability, codominant inheritance, abundance and multiallelic nature in plant genomes. However, unlike major food crops, limited genetic and genomic resources exist for improvement of forage crops especially for $T$. alexandrinum. In this study, we 1) isolated and characterized SSR markers in T. alexandrinum, and 2) investigated the level of polymorphism and the extent of molecular diversity among 69 accessions of Trifolium. In addition, we used existing SSR markers developed from T. repens to investigate the molecular diversity in Trifolium.

\section{Materials and Methods}

\subsection{Plant Materials}

Seeds of 72 accessions of Trifolium were procured from the Western Australian and Southern Australian gene banks (part of the Australian Pastures Gene- 
bank-APG); however, three of them did not germinate (Table 1). Seed were sown in plastic pots in glass house condition at Wagga Wagga Agricultural Institute, Wagga Wagga, NSW Australia maintained at $18^{\circ} \mathrm{C} \pm 4^{\circ} \mathrm{C}$ (Figure 1). In order to validate the genetic identity of accessions, passport information on growth habit, shape of cotyledonary and the first true leaf; and number of leaflets at the seedling stage, was recorded at seedling stage. The plants were cut; leaving $5 \mathrm{~cm}$ growth from the base (soil surface) after 45 and 65 days of sowing to observe the regeneration potential.

\subsection{DNA Isolation}

Fifteen days after germination, 2 to $3 \mathrm{~g}$ of young leaf tissue was collected from at least 10 plants from each accession and frozen in liquid nitrogen. DNA was extracted following the phenol-chloroform extraction method [7].

\subsection{Isolation of SSR}

This work was accomplished at the Indian Grassland and Fodder Research Institute, Jhansi, India. A library enrichment protocol [8] based on the PCR amplification of genomic DNA with 5' anchored degenerate microsatellite primers KKVRVRV(GA)10, KKVRVRV(GGT)5, KKVRVRV(CA)10, KKVRVRV(AAT)6, KKVRVRV(GTG)6, KKVRVRV(GACA)5, and KKVRVRV(CAA)6 (where K = $\mathrm{G} / \mathrm{T}, \mathrm{V}=\mathrm{G} / \mathrm{C} / \mathrm{A}, \mathrm{R}=\mathrm{G} / \mathrm{A}$ ), was used to amplify $T$. alexandrinum (cv. Wardan) genomic DNA following [9]. Positive recombinant clones were used for plasmid DNA isolation following [7]. DNA sequencing (ABI 3700) of the clones was done using the Big Dye Terminator reaction kit (Applied Biosystems, USA).

\subsection{Primer Design and PCR Amplifications}

Primers flanking SSR motifs were designed using the PRIMER 3 software [10] having 18 - 24 nucleotides, $\mathrm{Tm}=50^{\circ} \mathrm{C}-62^{\circ} \mathrm{C}$ with an optimal of $56^{\circ} \mathrm{C}, 100-400 \mathrm{bp}$ PCR product, and an optimal 40\% G + C content. Primers were designated as IGFRI-SSR 1 to 15 and details are provided in Table 2. These primer-pairs, in addition to those developed previously from $T$. repens [11] were used for genetic diversity study. SSR primer sequences were synthesized from Sigma-Aldrich (Australia); the forward primers were tailed with M13 sequence (19 bp long) and labeled with fluorescent dyes following [12]. PCR amplifications were performed under the conditions described previously ([11]. SSR polymorphism was analyzed using Beckman Coulter CEQ ${ }^{\mathrm{TM}} 8000$ Genetic Analysis System according to [12]. Fragment analysis was done using three fluorescent labeled dyes i.e. D2, D3 and D4 with size standard 400 and SSR alleles scored on CEQ capillary electrophoresis.

\subsection{Data Analysis}

Fragments amplified with SSR primer-pairs were scored into binary format ("1" for presence and " 0 " for absence). Genetic similarity, based on allelic data, was 
Table 1. Trifolium accessions used in study and cluster groups as per dendogram (Figure 2).

\begin{tabular}{|c|c|c|c|c|c|c|}
\hline $\begin{array}{l}\text { Pot } \\
\text { No. }\end{array}$ & Species & Primary Name & APG Accession & Status & $\begin{array}{c}\text { Country of } \\
\text { Origin }\end{array}$ & $\begin{array}{l}\text { Cluster } \\
\text { Group }\end{array}$ \\
\hline \multicolumn{7}{|c|}{ SA GRC Lines } \\
\hline 1 & & & $593^{c}$ & $\mathrm{Gp}$ & & \\
\hline 2 & & & 594 & $\mathrm{Gp}$ & Afghanistan & A \\
\hline 3 & & & 595 & $\mathrm{Gp}$ & Afghanistan & B1 \\
\hline 4 & & & $596^{c}$ & $\mathrm{Gp}$ & & \\
\hline 5 & & & 598 & $\mathrm{Gp}$ & Turkey & B1 \\
\hline 6 & & & 667 & $\mathrm{Gp}$ & Portugal & B1 \\
\hline 7 & & & 668 & $\mathrm{Gp}$ & Portugal & B1 \\
\hline 8 & & & 669 & $\mathrm{Gp}$ & Portugal & B1 \\
\hline 9 & & & 670 & $\mathrm{Gp}$ & Portugal & B1 \\
\hline 10 & & & 671 & $\mathrm{Gp}$ & Portugal & B1 \\
\hline 11 & & & 673 & $\mathrm{Gp}$ & Portugal & B1 \\
\hline 12 & & & 674 & $\mathrm{Gp}$ & Portugal & B1 \\
\hline 13 & & & 675 & $\mathrm{Gp}$ & Portugal & B2 \\
\hline 14 & & & 676 & $\mathrm{Gp}$ & Portugal & B1 \\
\hline 15 & & & 677 & $\mathrm{Gp}$ & Portugal & B1 \\
\hline 16 & & & 678 & $\mathrm{Gp}$ & Portugal & B2 \\
\hline 17 & & & 679 & $\mathrm{Gp}$ & Portugal & B2 \\
\hline 18 & T. alexandrinum & & 700 & $\mathrm{Gp}$ & Israel & B2 \\
\hline 19 & & & 6168 & $\mathrm{Gp}$ & Portugal & B1 \\
\hline 20 & & & 8579 & $\mathrm{cv}$ & Israel & B1 \\
\hline 21 & & & 8582 & $\mathrm{Gp}$ & Israel & $\mathrm{D}$ \\
\hline 22 & & & $14,247^{\mathrm{c}}$ & $\mathrm{cv}$ & & \\
\hline 23 & & & 15,890 & $\mathrm{Gp}$ & Syria & B2 \\
\hline $24^{\mathrm{a}}$ & & & 15,892 & $\mathrm{Gp}$ & Iraq & G \\
\hline 25 & & & 19,675 & $\mathrm{Gp}$ & Afghanistan & B2 \\
\hline 26 & & & 19,678 & $\mathrm{Gp}$ & Afghanistan & B1 \\
\hline 27 & & & 24,502 & $\mathrm{cv}$ & Morocco & B2 \\
\hline 28 & & & 24,503 & $\mathrm{cv}$ & Morocco & B1 \\
\hline 29 & & & 24,545 & $\mathrm{Gp}$ & Tunisia & B1 \\
\hline $30^{\mathrm{a}}$ & & & 32,668 & $\mathrm{Gp}$ & Turkey & $\mathrm{F}$ \\
\hline 31 & & & 33,621 & Breeder line & Australia & B1 \\
\hline 32 & & & 33,622 & Breeder line & Australia & B2 \\
\hline $33^{\mathrm{b}}$ & & & 33,747 & $\mathrm{cv}$ & & $\mathrm{J}$ \\
\hline 34 & & & 33,875 & $\mathrm{cv}$ & & B1 \\
\hline 35 & & & 35,688 & $\mathrm{cv}$ & & $\mathrm{E}$ \\
\hline
\end{tabular}


D. R. Malaviya et al.

\section{Continued}

\begin{tabular}{lllcc}
\hline $36^{\mathrm{b}}$ & 36,369 & $\mathrm{Gp}$ & Israel & $\mathrm{I}$ \\
37 & 37,099 & $\mathrm{cv}$ & Saudi Arabia & $\mathrm{D}$ \\
38 & 41,596 & $\mathrm{Gp}$ & Morocco & $\mathrm{B} 2$ \\
39 & 42,936 & $\mathrm{cv}$ & Italy & $\mathrm{C}$ \\
40 & 45,313 & $\mathrm{Gp}$ & Pakistan & $\mathrm{B} 2$ \\
41 & 45,314 & $\mathrm{cv}$ & & $\mathrm{B} 2$ \\
42 & 45,315 & $\mathrm{cv}$ & & $\mathrm{B} 1$ \\
43 & 45,316 & $\mathrm{cv}$ & & $\mathrm{B} 2$ \\
44 & 45,317 & $\mathrm{cv}$ & & $\mathrm{B} 1$ \\
45 & 45,318 & $\mathrm{cv}$ & & $\mathrm{B} 1$ \\
46 & 45320 & $\mathrm{cv}$ & Italy & $\mathrm{B} 2$
\end{tabular}

\section{WA GRC Lines}

\begin{tabular}{|c|c|c|c|c|c|c|}
\hline 47 & & 138978 & 80,647 & $\mathrm{Gp}$ & Morocco & $\mathrm{B} 2$ \\
\hline 48 & & 139496 & 75,354 & $\mathrm{Gp}$ & USA & $\mathrm{B} 2$ \\
\hline 49 & & 144658 & 77,737 & $\mathrm{Gp}$ & Israel & $\mathrm{C}$ \\
\hline 50 & & 018742 & 76,777 & $\mathrm{Gp}$ & & $\mathrm{B} 1$ \\
\hline 51 & & 034544 & 73,590 & $\mathrm{Gp}$ & Israel & $\mathrm{E}$ \\
\hline $52^{\mathrm{b}}$ & & 086555 & 77,740 & $\mathrm{Gp}$ & Israel & $\mathrm{B} 1$ \\
\hline 53 & & 086558 & 77,741 & $\mathrm{Gp}$ & Israel & B2 \\
\hline 54 & & 086566 & 77,742 & $\mathrm{Gp}$ & Portugal & $\mathrm{B} 1$ \\
\hline $55^{\mathrm{b}}$ & & 086756 & 77,743 & $\mathrm{Gp}$ & Israel & $\mathrm{B} 1$ \\
\hline $56^{\mathrm{b}}$ & $T$ Throndrinu & 087277 & 75,011 & $\mathrm{Gp}$ & & B2 \\
\hline $57^{\mathrm{b}}$ & 1. алеханантит & 087361 & 68,947 & $\mathrm{Gp}$ & & $\mathrm{H}$ \\
\hline 58 & & 93MAR264ALE & 73,299 & $\mathrm{Gp}$ & Morocco & B1 \\
\hline 59 & & 93MAR60ALE & 73,308 & Gp & Morocco & $\mathrm{E}$ \\
\hline 60 & & CQ1166 & 63,256 & $\mathrm{Gp}$ & & $\mathrm{B} 1$ \\
\hline 61 & & $\mathrm{CS} / 1 / 82$ & 73,410 & $\mathrm{Gp}$ & & $\mathrm{B} 1$ \\
\hline 62 & & Italy.ALE & 77,746 & $\mathrm{Gp}$ & & $\mathrm{C}$ \\
\hline 63 & & L59-72 & 77,747 & $\mathrm{Gp}$ & & B1 \\
\hline $64^{\mathrm{b}}$ & & LA YAPA INTA & 75,014 & $\mathrm{Gp}$ & & $\mathrm{H}$ \\
\hline 65 & & Sacromonte & 62,041 & $\mathrm{Gp}$ & & $\mathrm{B} 1$ \\
\hline 66 & & Warden & 76,306 & $\mathrm{cv}$ & India & $\mathrm{B} 1$ \\
\hline 67 & T. salmoneum & 087360 & 73,734 & $\mathrm{Gp}$ & & $\mathrm{B} 1$ \\
\hline 68 & T. subterraneum & $\begin{array}{c}\text { Dalkeith } \\
\text { subclover }\end{array}$ & 17,496 & $\mathrm{cv}$ & & $\mathrm{B} 1$ \\
\hline 69 & T. alexandrinum & Elite II & 35,688 & $\mathrm{cv}$ & & $\mathrm{J}$ \\
\hline 70 & T. vesiculosum & $\begin{array}{c}\text { Arrow leaf } \\
\text { clover }\end{array}$ & 78,434 & $\mathrm{cv}$ & & K \\
\hline 71 & T. michelianum & Boltabalansa & 32,860 & $\mathrm{cv}$ & & $\mathrm{L}$ \\
\hline 72 & T. repens & Haifa white & 63,892 & $\mathrm{cv}$ & & $\mathrm{K}$ \\
\hline
\end{tabular}

${ }^{a}$ Prostrate and slow growing; ${ }^{b}$ Morphologically close to T. salmoneum; 'No germination; Gp: Germplasm; cv: Cultivar. 

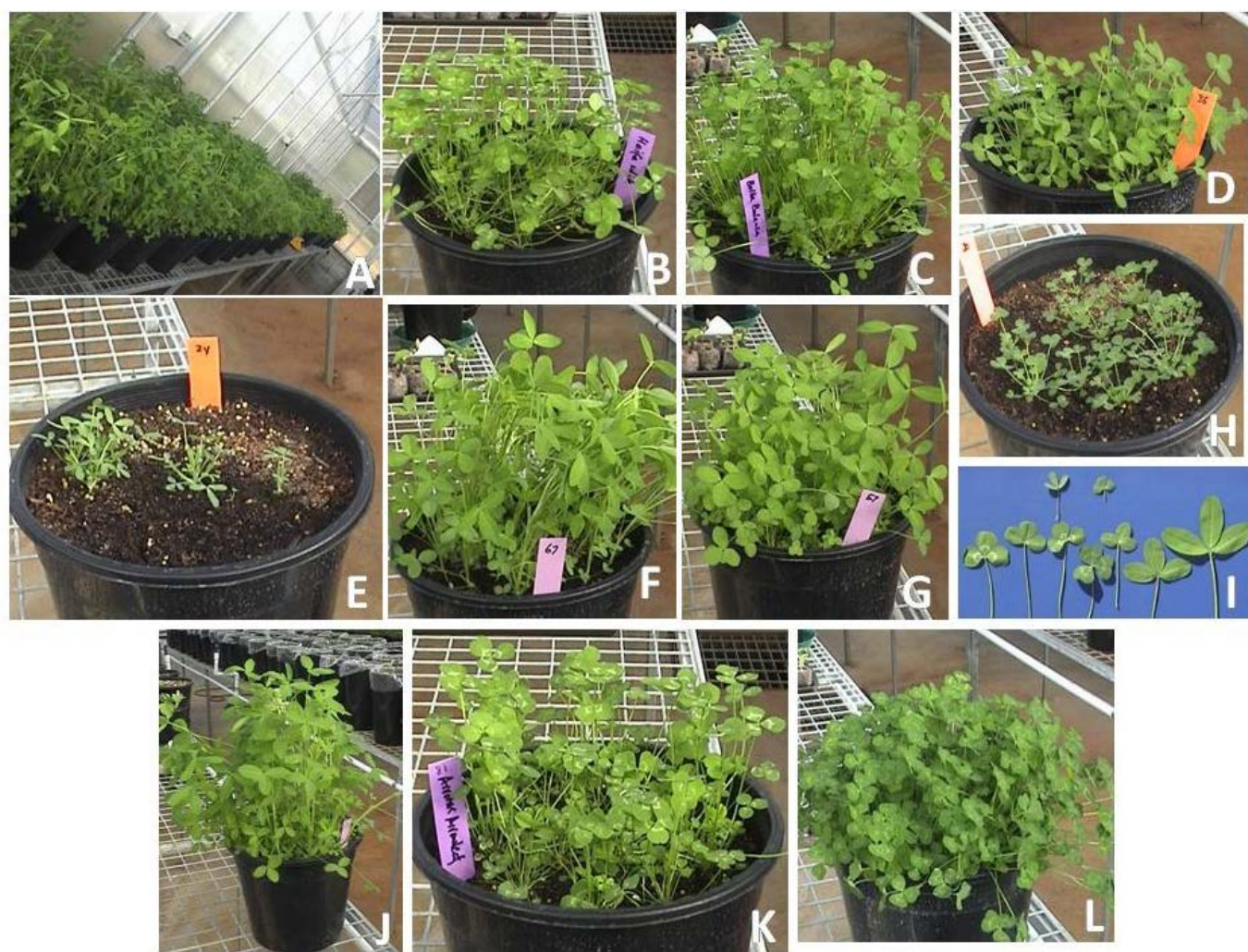

Figure 1. Trifolium germplasm growing in glasshouse at NSW DPI, Wagga Wagga: A general view (A), $T$. repens (B), T. michelianum (C), T. alexandrinum (no 36369) (D), T. alexandrinum (No 15892) (E), $T$. salmoneum (087360) (F), T. alexandrinum (087361) (G), T. alexandrinum (No 32668) (H), Variation in leaf shape and marker (I), T. alexandrinum (J), T. vesiculosum (K), T. subterraneum (L).

estimated following [13]. Dendogram was prepared following SAHN clustering based on unweighted pair-group method with arithmetic average (UPGMA) method using the NTSYS PC software

(http://www.exetersoftware.com/cat/ntsyspc/ntsyspc.html). The clusters in the dendogram were identified by drawing phenetic line at 0.5 similarity coefficient and considering the dedogram topologies, i.e. groups joining the other major group coinciding with the cutting points at root level. Polymorphic information content (PIC) was calculated as per [14].

\section{Results and Discussion}

\subsection{Development of Genomic SSR Markers in Egyptian Clover}

Amplicons generated through the five degenerate primers having (GA)10, (CT)10, (GTG)6, (GACA)5 and (CAA)6 repeats, were cloned and 89 colonies obtained. Of the 59 positive clones, 46 had inserts containing one or more SSR repeat motifs, suggesting that our approach for library construction was effective in isolation of SSR. Redundant clones visualized after BLAST analysis were removed. Although sequence analysis revealed all recombinants to possess terminal microsatellite repeats, to avoid any base pair degeneracy in degenerate primers, synthesis of forward and reverse primers was done; which helped in get- 
ting better cross-species reaction. The SSR motifs comprised of mononucleotide (T), dinucleotide (CA), tetranucleotides and compound repeats (Table 2). In all, 15 SSR primer pairs (IGFRI-SSR1 to 15), including 5 SSRs having compound repeats, were designed (Table 2). Degenerate primers are largely designed based on the common repeat sequences observed in plant genome and have been reported

Table 2. Sequences of $T$. alexandrinum primer pairs of SSR developed.

\begin{tabular}{|c|c|c|c|}
\hline Locus/Primer name & SSR motif & Expected fragment size (bp) & Primer sequence ( $5^{\prime}$ to $3^{\prime}$ ) \\
\hline \multirow[t]{2}{*}{ IGFRI-SSR1 } & $(\mathrm{AACC}) 3$ & 139 & GATGCTGGAATTGGAAGAGAAT(F) \\
\hline & & & CTTGAACCAACCAACCAGTACA(R) \\
\hline \multirow[t]{2}{*}{ IGFRI-SSR2 } & $(\mathrm{AACC}) 3 \mathrm{~N}^{\star} .(\mathrm{GGTT}) 3$ & & GCTGTGTGATTACTGCTTGGAG(F) \\
\hline & & & GCTGATCTTATCTCTAATGGGAAGAG(R) \\
\hline \multirow[t]{2}{*}{ IGFRI-SSR3 } & $(\mathrm{ACCA}) 3$ & 189 & AACTTCTTCCCCATCAGTTTCA(F) \\
\hline & & & ACCAACCAACCAAGATGACC(R) \\
\hline \multirow[t]{2}{*}{ IGFRI-SR4 } & $(\mathrm{AACC}) 3 \mathrm{~N}^{\star} .(\mathrm{GGTT}) 3$ & 317 & GTTAAGAAATCCTGTGGGCAAG(F) \\
\hline & & & GAAGAAAGGAGCGAAAACAGAC(R) \\
\hline \multirow[t]{2}{*}{ IGFRI-SSR5 } & $(\mathrm{ATGT}) 12 \mathrm{~N}^{*} .(\mathrm{AACC}) 3$ & 337 & CATCGGTTGGTTGGTTGG(F) \\
\hline & & & TCGTACATTAACATGCGTGACC(R) \\
\hline \multirow[t]{2}{*}{ IGFRI-SSR6 } & $(\mathrm{GGTT}) 3$ & 296 & ATTAAAACCGAACCAACCAACC(F) \\
\hline & & & AAGATGTGACCAACCAACCAAC(R) \\
\hline \multirow[t]{2}{*}{ IGFRI-SSR7 } & $(\mathrm{AACC}) 3 \mathrm{~N}^{\star} .(\mathrm{GGTT}) 3$ & 320 & GGTTAATTGGTCACGCATGTT(F) \\
\hline & & & TTGAAGCAATCTAGTCAGGCAG(R) \\
\hline \multirow[t]{2}{*}{ IGFRI-SSR8 } & $(\mathrm{AACC}) 3$ & 225 & GAAAGGAGGCCACACAGAACT(F) \\
\hline & & & TCATACAACCAACCAACCAAGA(R) \\
\hline \multirow[t]{2}{*}{ IGFRI-SSR9 } & (TTGG)3 & 259 & ACTTAAACCAACCAACCGGAA(F) \\
\hline & & & GCCCСАTATTCССТCACTAAAC(R) \\
\hline \multirow[t]{2}{*}{ IGFRI-SSR10 } & $(\mathrm{T}) 10$ & 300 & GAAATCTTGGTTGGTTGGTTGT(F) \\
\hline & & & CACTAAAGGGTTCCATTCCATT(R) \\
\hline \multirow[t]{2}{*}{ IGFRI-SSR11 } & $(\mathrm{T}) 10$ & 151 & AATGGAATGGAACCCTTTAGTG(F) \\
\hline & & & TGCATGTGGAAAATACCTTCAG(R) \\
\hline \multirow[t]{2}{*}{ IGFRI-SSR12 } & $(\mathrm{CCAA}) 3 \mathrm{~N}^{\star} \cdot(\mathrm{GGTT}) 3$ & 274 & AACTCCСCTCTCCTCTGCTAGT(F) \\
\hline & & & CATGATATACGGACCACCTGC(R) \\
\hline \multirow[t]{2}{*}{ IGFRI-SSR13 } & $(\mathrm{AACC}) 3$ & 240 & GGTCACGCATGTTAATGTACGA(F) \\
\hline & & & CATAACCAACCAACCGGAACT(R) \\
\hline \multirow[t]{2}{*}{ IGFRI-SSR14 } & $(\mathrm{GGTT}) 3$ & 167 & TGAACCAACCAACCTGGAGT(F) \\
\hline & & & GGCAGCATTAGCCTTTCTTTTA(R) \\
\hline \multirow[t]{2}{*}{ IGFRI-SSR15 } & $(\mathrm{CA}) 20$ & 229 & GGGGACTCTCTCTCTCTCTCTC(F) \\
\hline & & & GCGTGATTCCTTTCCACA(R) \\
\hline
\end{tabular}

${ }^{\star} \mathrm{N}-\mathrm{A} / \mathrm{C} / \mathrm{G} / \mathrm{T}, \mathrm{bp}=$ base pair. 
working with different legume and grass species [9]. Thus, the results demonstrate the utility of degenerate 5 ' anchored primers as simple, fast and cost effective as reported earlier also by [9].

\subsection{SSR Polymorphism and Cross Transferability in Trifolium}

Of the 15 IGFRI-SSR primer pairs (Table 2), derived from T. alexandrinum in this study, seven amplified the fragments of expected sizes in Egyptian clover. We further analyzed 7 polymorphic SSR markers to reveal allelic diversity in 69 accessions of the different Trifolium species. A total of 20 alleles were detected by the seven IGFRI-SSR markers (Table 3). The size of SSR alleles varied from

Table 3. SSR alleles scored on CEQ capillary electrophoresis.

\begin{tabular}{|c|c|c|c|c|c|c|c|c|c|}
\hline Primer name & $\begin{array}{c}T . \\
\text { alexandrinum } \\
\text { (bp) }\end{array}$ & $\begin{array}{c}T . \\
\text { salmoneum } \\
\text { (bp) }\end{array}$ & $\begin{array}{c}T . \\
\text { subterraneum } \\
\text { (bp) }\end{array}$ & $\begin{array}{c}T . \\
\text { vesiculosum } \\
\text { (bp) }\end{array}$ & $\begin{array}{c}T . \\
\text { michelianum } \\
\text { (bp) }\end{array}$ & $\begin{array}{l}\text { T. repens } \\
\text { (bp) }\end{array}$ & $\begin{array}{l}\text { Accessions } \\
\text { with doubtful } \\
\text { identity } \\
\text { (bp) }\end{array}$ & PIC & $\begin{array}{c}\text { No. of } \\
\text { fragments }\end{array}$ \\
\hline \multicolumn{10}{|c|}{ T. repens primers } \\
\hline А02H09 & & & & $211-213$ & 213 & $211-213$ & & 0.99 & 2 \\
\hline A01C10 & $287-289$ & $287-289$ & $287-289$ & $238-289$ & & $238-289$ & $287-318$ & 0.82 & 8 \\
\hline A04F01 & $182-202$ & $182-192$ & 192 & $192-234$ & 192 & $192-234$ & 192 & 0.89 & 7 \\
\hline A01H11 & $138-175$ & $138-144$ & $138-144$ & $175-245$ & $138-169$ & $169-242$ & $138-144$ & 0.95 & 8 \\
\hline $\mathrm{A} 02 \mathrm{D} 12$ & $237-247$ & & & $146-148$ & 148 & $146-247$ & $237-247$ & 0.97 & 6 \\
\hline A05A09 & $168-197$ & & & $193-197$ & $168-205$ & $176-197$ & $179-205$ & 0.98 & 4 \\
\hline B01B05 & $121-269$ & $121-265$ & 123 & $235-269$ & $263-267$ & $235-269$ & $121-269$ & 0.89 & 10 \\
\hline A06E06 & $131-161$ & $131-161$ & $131-161$ & $137-175$ & $131-144$ & $137-175$ & $131-263$ & 0.91 & 13 \\
\hline A06B04 & $165-194$ & $173-175$ & & $173-175$ & $185-194$ & $173-199$ & $165-199$ & 0.84 & 8 \\
\hline A02D07 & $165-182$ & 165 & 165 & $165-182$ & & $165-182$ & $165-182$ & 0.97 & 7 \\
\hline B02E01 & $133-177$ & $139-143$ & & $135-137$ & $135-177$ & $127-137$ & 177 & 0.97 & 7 \\
\hline B01E07 & $137-189$ & & 181 & $233-235$ & 235 & $233-235$ & $137-235$ & 0.89 & 6 \\
\hline A04B12 & $254-258$ & $254-258$ & $254-258$ & $258-278$ & 278 & $266-278$ & $250-258$ & 0.84 & 8 \\
\hline A03B05 & $122-166$ & $126-130$ & $126-136$ & $126-166$ & $122-134$ & $122-166$ & $128-166$ & 0.96 & 10 \\
\hline А02H03 & & & & $232-234$ & & $232-240$ & 236 & 0.99 & 5 \\
\hline \multicolumn{10}{|c|}{ T. alexandrinum primers } \\
\hline IGFRI-SSR3 & $133-189$ & & & & & $173-189$ & $165-189$ & 0.97 & 7 \\
\hline IGFRI-SSR7 & 251 & & 251 & 259 & & 251 & & 0.99 & 2 \\
\hline IGFRI-SSR8 & $250-262$ & & & & & & & 0.99 & 2 \\
\hline IGFRI-SSR11 & $168-172$ & $168-172$ & $168-172$ & $168-172$ & $168-172$ & $168-172$ & $168-172$ & 0.74 & 3 \\
\hline IGFRI-SSR13 & $168-176$ & $168-176$ & $168-176$ & $168-176$ & & $168-176$ & $168-176$ & 0.78 & 2 \\
\hline IGFRI-SSR14 & $158-170$ & & & & & & 158 & 0.99 & 2 \\
\hline IGFRI-SSR15 & $228-232$ & $228-232$ & $228-232$ & $228-232$ & & & $228-232$ & 0.68 & 2 \\
\hline
\end{tabular}

bp: base pair. 
133 to $262 \mathrm{bp}$ among $T$. alexandrinum accessions as well as across the different species. The number of alleles/SSR ranged from two to seven, with an average of 2.85 allele/SSR locus. The number of alleles/SSR among T. alexandrinum accessions ranged from one to seven with 2.71 alleles per SSR locus. PIC values observed with these primers ranged from 0.99 to 0.68 . Primer IGFRI-SSR 8 was species specific and polymorphic with $T$. alexandrinum. IGFRI-SSR 14 amplified fragments with $T$. alexandrinum and the two off type (prostrate and slow growing) $T$. alexandrinum accessions 15,892 and 33,747 (Figure $1(\mathrm{E})$ \& Figure $1(\mathrm{H})$ ). The remaining five IGFRI-SSRs amplified fragments with other species also. Alleles of IGFRI-SSR 11, 13 and 15 were represented among most of the accessions under study, thus, indicating common ancestral contribution of the alleles. T. michelianum was found to possess the most common fragments of IGFRI-SSR 11 only (Table 3), hence, showed high degree of dissimilarity with other accessions. These results suggest that SSR markers, derived from $T$. alexandrinum, are suitable to effectively discriminate different Trifolium species.

To validate the usefulness of $T$. repens primers and to assess molecular diversity among Trifolium species, we analyzed second set of 15 SSR markers developed from $T$. repens [11]. Thirteen out of these 15 primers amplified fragments with T. alexandrinum; all 15 amplified with arrow clover; 10 with T. salmoneum, 9 with T. subterraneum and 13 with T. michelianum. A total of 109 alleles were scored (Table 3 ) which was attributed to the diverse genetic background of the accessions under the present study. More than 0.9 PIC values were noticed for 8 out of 15 primer pairs and the minimum PIC value of 0.82 was noticed with primer A01C10. Most of these primers amplified fragments with other species also. A02H09 and A02H03 primers did not amplify the DNA from T. alexandrinum, T. salmoneum, T. subterraneum and the morphologically T. salmoneum look-alike accessions (Table 1), thus suggesting a genetic relatedness among them. A few primers produced 6 to 10 alleles among T. alexandrinum accessions (Table 3) which was attributed to diverse genetic base of the $T$. alexandrinum accessions and that the accessions from different place of collection might be having allelic contribution from different Trifolium species. It is also possible that the primers could bind at many locations due to pleiotropism or non-specificity of the primers. Molecular studies on two ecotypes of Berseem as done by [15] also found that QTLs for different traits were mapped in the same region on map, thus, indicating common genetic control and possibility of pleiotropism and/or tight linkage of different polygenes or QTLs. The extent of genetic diversity in the present set of germplasm was larger than that assessed by morphological and isozyme studies among Indian collection of T. alexandrinum germplasm [7] [16]. This can be attributed to factors such as the diverse source of the germplasm, the efficacy of SSR primers and possible different pathway of origin of these germplasm lines.

In all, the two sets of primers proved to be effective in revealing the intra and the interspecies diversity. Additionally, high polymorphism exhibited among $T$. alexandrinum accessions indicated suitability of these SSRs for further allelic 
study of the species.

\subsection{Genetic Relationship among Accessions}

In order to investigate the genetic relationship among accessions of $T$. alexandrinum and related species, we generated dendogram using clustering method. Twelve distinct clusters were formed containing a varying number of accessions (Figure 2). T. alexandrinum accession No 594 formed independent cluster "A" (Figure 2), although this accession was morphologically similar to other Egyptian clover accession. Cluster "B", the largest cluster was divided in two sub-clusters "B1" and "B2" containing 33 and 17 accessions respectively. The majority of T. alexandrinum accessions together with T. salmoneum, T. subterraneum and the three T. salmoneum type accessions (75,011, 77,743, 77,740) grouped in this cluster. Cluster "C", "D" and " $\mathrm{E}$ " contained three, two and three T. alexandrinum accessions respectively. Although, T. alexandrinum accessions represented different geographical places, no trend of clustering based on place

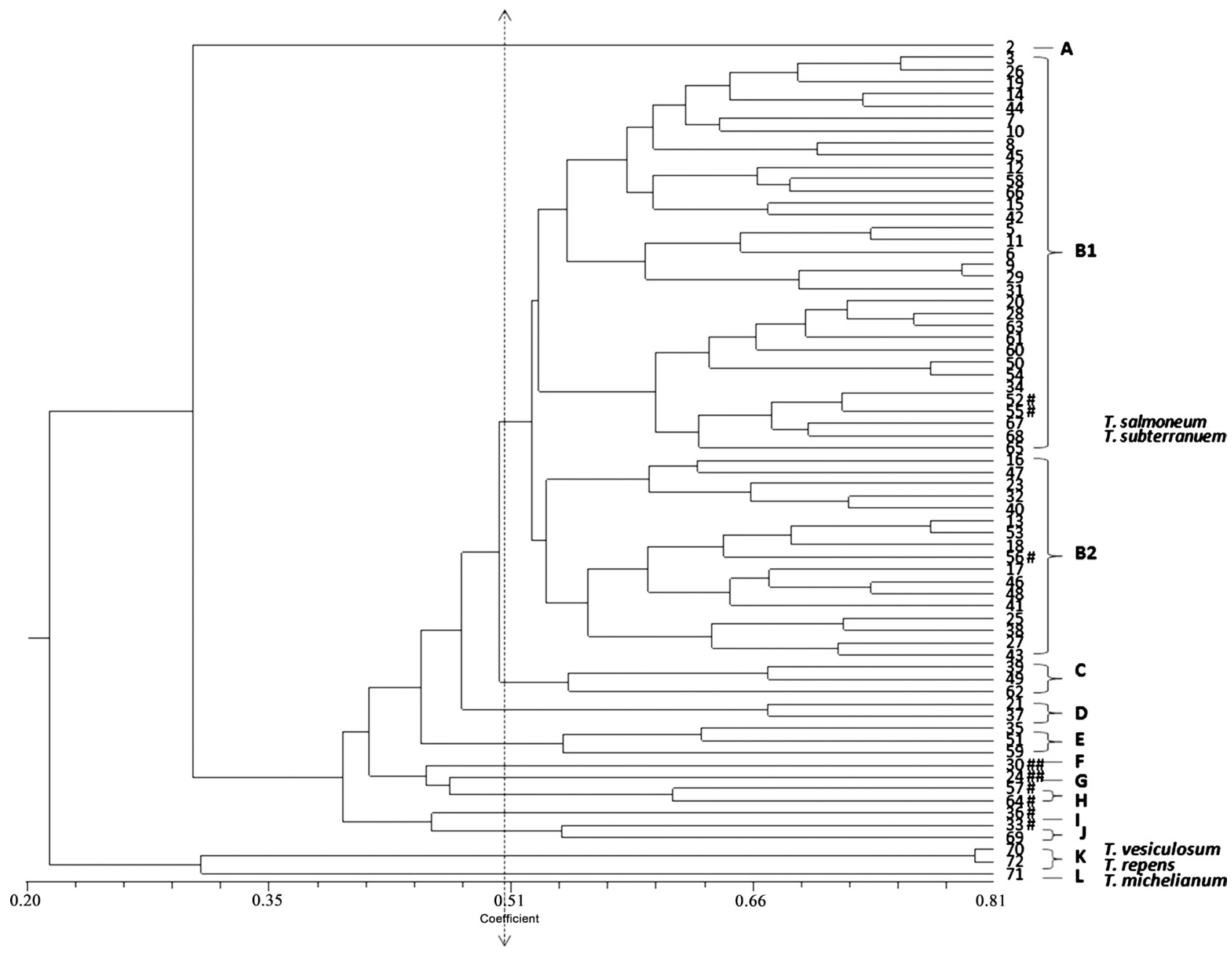

Figure 2. Dice similarity based dendogram showing clustering of Trifolium accession: Similarity coefficient is on "x" axis and accession numbers as per serial numbers in Table 1 on axis " $y$ "; Dotted phenetic line drawn at 0.5 similarity coefficient; \#: $T$. alexandrinum accession close to T. salmoneum plant type; \#\#: prostrate and slow growing T. alexandrinum accessions. 
of collection was established. This might be because of movement of germplasm and its intermixing with native germplasm. Two prostrate and slow growing $T$. alexandrinum accessions 32,668 and 15,892 formed independent clusters "F" and "G" respectively. These two accessions were having no morphological similarity with $T$. alexandrinum. T. alexandrinum accessions, possessing morphological similarity with T. salmoneum, 68,947 and 75,014 formed cluster "H"; accession 36,369 formed independent cluster "I" whereas accession 33,747 formed cluster "J" with an T. alexandrinum cv Elite II. Cluster " $F$ ", "G" and " $H$ " grouped together before joining the major cluster. Similarly, cluster "J" and "I" also grouped together before joining the major cluster. These $T$. alexandrinum accessions which differed in morphology were placed closely in the dendogram. Cluster " $K$ " possessed the two species $T$. vesiculosum and T. repens whereas cluster "L" was represented with T. michelianum only.

The genus Trifolium has been divided in eight sections [1]. In the present study, clustering of $T$. subterraneum belonging to section Trichocephalum of the genus, with T. alexandrinum and T. salmoneum of section Trifolium, indicated that the three species possessed relatedness which was congruent with earlier reports [3] [16] [17] [18] [19]. In fact, Lotoidea is the largest section and has served as source taxa for the evolution of many other sections [1]. This is also supported with development of fertile intersection interspecific crosses [10] [20] [21]. Thus, this study reaffirms the high relatedness of the species as well as possibility of polyphyletic origin of $T$. alexandrinum.

Origin and ancestry of T. alexandrinum has remained controversial. T. berytheum [22] [23], T. echinatum [24], T. apertum [18] and T. salmoneum [23] were considered as its progenitor. In the present study, clustering of $T$. salmoneum and the $T$. salmoneum look-a-like accessions with $T$. alexandrinum accessions also indicated close affinity between the two species and that $T$. salmoneum might have contributed in evolution of $T$. alexandrinum. Clustering of T. alexandrinum Elite II, an Australian cultivar, with two T. salmoneum type accessions also suggested its ancestry with the former. In fact, the accessions mentioned as "T. salmoneum type" were phenotypically closer to T. salmoneum and possessed round cotyledonary leaves similar to T. salmoneum. Thus, the molecular data based similarity was congruent with phenotype of the plants.

Boundaries among different Trifolium species are extremely difficult to define because of the range of diversity caused by primary polymorphism [25]. Hence, identification of species is an important aspect in Trifolium genetic resource study. Occurrence of a few plants, either with serrated margin first leaf or bifoliate/trifoliate first leaf among accessions 668, 45,313, 669, 35,688, 73,308 and 77,740 of $T$. alexandrinum, were considered as admixtures which occurs as samples are collected from the field. However, the diversity as result of admixture can also be conserved because the basic objective of any gene bank is to conserve genetic diversity. Occasional occurrence of plants with a few multifoliate leaves in accessions $673,6,3256$ and 33,875 was in line with such reports in many Tri- 
folium species. The genetics of the trait is not known, although pentafoliate trait was recently fixed in T. alexandrinum [26].

Thus, this study developed a set of primer-pairs which have shown to amplify alleles from $T$. alexandrinum, $T$. salmoneum, $T$. vesiculosum, $T$. michelianum, T. repens and T. subterraneum, suggesting that this newly developed resource is useful for assessing molecular diversity among accessions of at least six Trifolium species. The seven SSR markers from $T$. alexandrinum genomic resource and 15 from $T$. repens genomic resource were able to distinguish different accessions of $T$. alexandrinum and the species under study. Allelic dissimilarity among morphologically similar accessions (accession 594, a typical T. alexandrinum, forming independent cluster) and clustering together of morphologically distinct accession (Elite II and accession Nos. 33,747 and 36,369) shows the efficiency of SSR primers in the study. High PIC value of SSR proves that these markers were suitable to differentiate among accessions. Cluster analysis indicated suitability of SSR markers for genome analysis. The study could successfully establish the larger diversity of the T. alexandrinum gene pool as superior resource for further breeding and enriching the SSR markers repertoire for further genetic study. The study also established the relatedness of T. subterraneum and $T$. salmoneum accession with $T$. alexandrinum, indicating their role in the evolution of T. alexandrinum.

\section{Limitations of Study}

Five species of Trifolium, other than T. alexandrinum, were represented by single accession because of primary interest to characterize the $T$. alexandrinum germplasm. The interspecific lineage discussed in the study may be more emphatically established with representation of more number of accessions of related species. Although the limited number of SSR primers used in the study could effectively differentiate among species, studies with more SSRs will help exposing intra-species variation and contribution of different species in development of cultivars/ germplasm.

\section{Acknowledgements}

DRM is thankful to Department of Biotechnology, India for Overseas Associateship and Graham Centre for Agricultural Innovation, Wagga Wagga NSW, Australia for agreeing to carrying out this research. Authors are also thankful to Department of Biotechnology, India for financial support to network project.

\section{Conflicts of Interest}

The authors declare that there is no conflict of interest.

\section{References}

[1] Zohary M. and Heller D. (1984) The Genus Trifolium. The Israel Academy of Sciences and Humanities, Jerusalem. 
[2] Muhammad, D., Misri, B., EL-Nahrawy, M., Khan, S. and Serkan, A. (2014) Egyptian Clover (Trifolium alexandrinum)-King of Forage Crops. Food and Agriculture Organization of the United Nations, Regional Office for the Near East and North Africa Cairo, 127.

[3] Malaviya, D.R., Kumar, B., Roy, A.K., Kaushal, P. and Tiwari, A. (2005) Estimation of Variability for Isozymes of Five Enzyme Systems among Wild and Cultivated Species of Trifolium. Genetic Resources and Crop Evolution, 52, 967-976. https://doi.org/10.1007/s10722-003-6127-0

[4] Malaviya, D.R., Roy A.K., Kaushal, P., Singh, U.P. and Kumar, B. (2007) Phenotypic Variability among the Germplasm Lines of Egyptian Clover (Trifolium alexandrinum L.). Journal of Plant Genetic Resources, 20, 15-20.

[5] Kumar, B., Malaviya, D.R., Roy, A.K. and Kaushal, P. (2008) Isozyme Variability in Trifolium alexandrinum Accessions. Indian Journal of Genetics and Plant Breeding, 68, 195-200.

[6] Verma, P., Chandra, A., Roy, A.K., Malaviya, D.R., Kaushal, P., Pandey, D. and Bhatia, S. (2015) Development and Characterization of Genomic Based SSR Markers in Berseem (Trifolium alexandrinum L.), an Important Multi-Cut Annual Forage Legume. Molecular Breeding, 35, 23. https://doi.org/10.1007/s11032-015-0223-7

[7] Sambrook, J., Fritsch, E.F. and Maniatis, T. (1989) Molecular Cloning. A Laboratory Manual. 2nd Edition, Cold Spring Harbour Laboratory Press, New York.

[8] Fisher, P.J., Gardner, R.C. and Richardson, T.E. (1996) Single Locus Microsatellites Isolated Using 5' Anchored PCR. Nucleic Acids Research, 24, 4369-4371. https://doi.org/10.1093/nar/24.21.4369

[9] Chandra, A., Tiwari, K.K., Nagaich, D., Dubey, N., Kumar, S. and Roy, A.K. (2011) Development and Characterization of Microsatellite Markers from Tropical Forage Stylosanthes Species and Analysis of Genetic Variability and Cross-Species Transferability. Genome, 54, 1016-1028. https://doi.org/10.1139/g11-064

[10] Rozen, S. and Skaletsky, H. (1999) Primer3 on the WWW for General Users and for Biologist Programmers. Methods in Molecular Biology, 132, 365-386. https://doi.org/10.1385/1-59259-192-2:365

[11] George, J., Dobrowolski, M.P., van Zijll de Jong, E., Cogan, O.I., Smith, K.F. and Forster, J.W. (2006) Assessment of Genetic Diversity in Cultivars of White Clover (Trifolium repens L.) Detected by SSR Polymorphism. Gemone, 49, 919-930. https://doi.org/10.1139/g06-079

[12] Raman, R., Raman, H., Johnstone, K., Lisle, C., Smith, A., Martin, P. and Allen, H. (2005) Genetic and in Silico Comparative Mapping of the Polyphenol Oxidase Gene in Bread Wheat (Triticum aestivum L.). Functional and Integrated Genomics, 5, 185-200. https://doi.org/10.1007/s10142-005-0144-3

[13] Dice, L.R. (1945) Measures of the Amount of Ecological Association Behaviour Species. Ecology, 26, 297-302. https://doi.org/10.2307/1932409

[14] Anderson, J.A., Churchill, G.A., Autrique, J.E., Tanksley, S.D. and Sorrells, M.E. (1993) Optimizing Parental Selection for Genetic Linkage Maps. Genome, 36, 181-186. https://doi.org/10.1139/g93-024

[15] Abdel-Fatah, B.E.S and Bakheit, B.R. (2018) Genetic Diversity between Two Egyptian Clover Varieties and QTL Analysis for Some Agro-Morphological Traits. Molecular Biology Reports. https://doi.org/10.1007/s11033-018-4546-4

[16] Malaviya, D.R., Roy, A.K., Kaushal, P., Kumar, B. and Tiwari, A. (2008) Genetic Si- 
milarity among Trifolium Species Based on Isozyme Banding Pattern. Plant Systematics and Evolution, 276, 125-136. https://doi.org/10.1007/s00606-008-0070-7

[17] Badr, A., El-Shazly, H.H. and Watson, L.E. (2008) Origin and Ancestry of Egyptian Clover (Trifolium alexandrinum L.) as Revealed by AFLP Markers. Genetic Resource and Crop Evolution, 55, 21-31. https://doi.org/10.1007/s10722-007-9210-0

[18] Bobrov, E.G. (1947) Vidi Kleverov URSS. Acta Inst. Bot. N. Acad. Sci. USSR Ser1, 6, 164-336. (In Russian)

[19] Malaviya, D.R., Roy, A.K., Kaushal, P., Chakraborti, M., Yadav, A., Khare, A., Dhir, R., Khairnar, D. and George, G.P. (2018) Interspecific Compatibility Barriers, Development of Interspecific Hybrids through Embryo Rescue and Lineage of Trifolium alexandrinum (Egyptian Clover) - Important Tropical Forage Legume. Plant Breeding, 137, 655-672. https://doi.org/10.1111/pbr.12616

[20] Kaushal, P., Malaviya, D.R., Roy, A.K., Kumar, B. and Tiwari, A. (2005) Trifolium alexandrinum $\times T$. resupinatum Interspecific Hybrids Developed through Embryo Rescue. Plant Cell, Tissue and Organ Culture, 83, 137-144. https://doi.org/10.1007/s11240-005-4442-1

[21] Kaur, A., Kaur, K.P., Kalia, A., Rani, U., Kahlon, J.G., Sharma, R., Malaviya, D., Kapoor, R. and Sandhu, J.S. (2017) Generation of Interspecific Hybrids between Trifolium vesiculosum and T. alexandrinum Using Embryo Rescue. Euphytica, 213, 253.

[22] Oppenheimer, H.R. (1959) The Origin of Egyptian Clover with Critical Revision of Some Related Species. Bulletin of the Research Council of Israel, 7D, 202-221.

[23] Putiyevsky, E., Katznelson, J. and Zohary, M. (1975) Cytogenetic Studies in Trifolium spp. Related to Berseem. IV. The Relationships in the Alexandrinum and Vavilovii Crossability Groups and the Origin of Cultivated Berseem. Theoretical \& Applied Genetics, 45, 355-362. https://doi.org/10.1007/BF00277676

[24] Aaronsohn, A. (1910) Agricultural Explorations in Palestine. USDA-Bureau of Plant Industry, Bulletin No. 180.

[25] Zohary, M. (1972) Origin and Evolution in the Genus Trifolium. Botaniska Notiser, 125, 501-511.

[26] Pathak, S., Malaviya, D.R., Roy, A.K., Dwivedi, K. and Kaushal, P. (2015) Multifoliate Leaf Formation in Induced Tetraploids of Trifolium alexandrinum L. Cytologia, 80, 59-66. https://doi.org/10.1508/cytologia.80.59 